\title{
To the Memory of Pavel Dzhibraelovich Sarkisov
}

On April 25, 2012, Pavel Dzhibraelovich Sarkisov, Full Member of the Russian Academy of Sciences, President of the D. I. Mendeleev Russian Chemical Society, President of the D. I. Mendeleev University of Chemical Technology of Russia passed away at the age of 79 after siege of illness. It is a grievous loss for Russian science and higher education.

P. D. Sarkisov was a leading scientist in the physical chemistry, technology, and industrial production of silicate and refractory non-metallic materials. His name is associated with many new areas of silicate material science. He developed the fundamentals of controlled crystallization of glasses and silicate melts for new structural and functional glassycrystalline materials, formulated the principles and key regularities of their synthesis, created the engineering grounds for the production of structural, decorative, and special glasses, glass ceramics, and composites. Under P. D. Sarkisov's direction and with his personal participation, resource- and energy-effective industrial processes and continuous production lines for the manufacture of slag glass-ceramics, the decorative glass ceramic material Sigran, and technical-grade glass ceramics were developed and commercialized at the Konstantinov plant "Automobile Glass" (Donetsk Region). Among these, there was the world first process line for continuous rolling of sheet slag glass-ceramics based on blastfurnace slag.

P. D. Sarkisov headed the top school of thought in the field of nanostructured glass, non-linear optical and laser materials, glass ceramics with oriented structure, polar dielectrics, high-temperature composites on glass crystalline matrices, and protective coatings. Of great practical value are his works dealing with inorganic medical material science, which resulted in the development of biologically active calcium phosphate glass ceramics and composites for bone implants and cancer therapy. The results of many-year research carried out by P. D. Sarkisov and his followers have been internationally recognized and provided the basis for the foundation of the international scientific laboratory of glassbased functional materials. He is the author of more than 600 scientific publications, including tens of books, study guides, handbooks, patents, and inventions.

A major part of P. D. Sarkisov's creative biography is related to higher education and, first of all with the D. I. Mendeleev University of Chemical Technology of Russia where he started as research fellow and became rector and President of this top higher institution of Russia. A gifted teacher and scientific supervisor P. D. Sarkisov trained more than $50 \mathrm{Ph}$. Ds and Doctors of science. Under his direction, D. I. Mendeleev University of Chemical Technology turned into a multidisciplinary center for training engineers with high international rating and broad scientific relations with world top universities.

Being Chairman of Education and Methodics Association on the Chemical Engineering Education and Chairman of Science and Methodics Council in Chemistry at the RF Ministry of Education and Science, P. D. Sarkisov greatly contributed to the development of education in the chemical engineering and technology in Russia. In view of the need to extend the fundamental and specialized training of chemical engineers, he initiated the development of new organization principles of higher education and its state standards and renewal of education programs. He made a lot of effort for popularization of chemical knowledge in high school, engaging gifted students in scientific research and their rooting and career advancement in science.

Until very recently, P. D. Sarkisov worked on enhancing the role of chemistry and chemical engineering in the country economy, consolidation of chemical community, increase in the international reputation of Russian chemical science.

P. D. Sarkisov's scientific achievements and merits in educational and social activities were appreciated by awarding the RF and Ukrainian Soviet Socialist Republic State Prizes, the Prizes of RF President and Government, and I. V. Grebenshchikov Prize of the RAS. He was awarded the Labor Red Banner, Friendship, To the Merits for Fatherland, IV degree, Orders and V. G. Shukhov Gold Medal. P. D. Sarkisov was elected President of the UNESCO Center on the chemical science and education, Professor Emeritus and Honorary Doctor of Russian and foreign universities. One of minor planets of the Solar System was named after him.

The cherished memory of the outstanding scientist and talented treacher, and kind and remarkable person Pavel Dzhibraelovich Sarkisov will be kept fortever by his students, colleagues, and friends.

Published in Russian in Izvestiya Akademii Nauk. Seriya Khimicheskaya, No. 5, pp. 1042, May, 2012.

1066-5285/12/6105-1048 (C) 2012 Springer Science+Business Media, Inc. 